\title{
ИЗОБРАЖЕНИЕ ЛИТЕРАТУРНЫХ ГЕРОЕВ В ИЗБРАННЫХ ПРОИЗВЕДЕНИЯХ В. М. ШУКШИНА
}

\author{
Марианна Фигеды ьва
}

\section{REPRRSENTATION OF CHARACTERS FROM SELECTED SHUKSHIN'S LITERARY WORKS}

\author{
Marianna Figedyová
}

\begin{abstract}
Резюме: Статья посвящена передовому представителю русской деревенской прозы - Василию Макаровичу Шукшину. В работе анализируются функции фигуральных композиционных пар в избранных рассказах автора, исследуется их постепенное развитие и изменение жизненных целей представленных персонажей, а также рассматривается мотивация главных героев и условия для реализации их жизненных планов в обществе, применение теоретических основ в конкретной литературной интерпретации.
\end{abstract}

Ключевые слова: деревенская проза, Шукшин, фигуральная композиционная пара, мотивация героев

\begin{abstract}
The article is dedicated to the leading representative of Russian village prose, Vasily Shukshin. It focuses on the role of figural compositional pairs in the author's selected short prose, follows their gradual development and changes in the portrayed characters, deals with the motivation of the main characters and the social space for their realization. The fulfillment of the characteristics of village prose in a specific literary realization is studied as well.
\end{abstract}

Key words: village prose, Shukshin, figural compositional pair, motivation

DOI: $10.14712 / 9788076032088.8$

\section{Биография автора}

Василий Макарович Шукшин был родом из отдаленной части Советского союза - Алтайского края. Писатель родился в бедной крестьянской семье в 1929 году в деревне Сростки. Его считают одним из самых ярких представителей деревенской прозы. Уже будучи ребенком, он оказался в сложной жизненной ситуации. Его отец, Макар Леонтьевич Шукшин,в период насильственной коллективизации был арестован и в 1933 году расстрелян. В 1956 году был реабилитирован посмертно. Благодаря этой реабилитации, Василий Шукшин смог отдаленно затронуть спорный вопрос коллективизации в своем творчестве. На жизненном пути Василия Макровича Шукшина встречались сложные повороты. Автор был энергичным человеком, который пробивался через тернии жизни только собственными силами и способностями. Он часто менял места жительства, пробовал работу в различных областях: был рабочим, крестьянином, военным, учителем, директором деревенской школы. Писатель постоянно повышал свою квалификацию и образование. Шукшин пытался устроиться в Москве на должность писателя, учился в престижном Всероссийском государственном институте кинематографии имени С.А.Герасимова, который окончил в 1960 году. Он прожил короткую, но насыщенную жизнь. В. 
М. Шукшин умер в 1974 году в возрасте 45 лет во время съемок фильма режиссера Сергея Бондарчука по роману Михаила Шолохова «Они сражались за Родину». Его внезапная смерть вызвала и продолжает вызывать полемику дискутирующих.

Г.П. Бинова так отзывается о данном писателе: «Яркая творческая индивидуальность, не менее яркая жизненная биография, каторжная эксплуатация самого себя, внезапная смерть все "работало" на создание легенды о Шукшине. Одним из главных элементовфеномена Шукшина была его необыкновенная разносторонность. В наш век, век узкой специализации, такая творческая многогранность не можетне удивлять и не восхищать. Писатель, сценарист, режиссер, постановщик, актер широкого диапазона. Не всем, вероятно, известно, что писал Шукшин и стихи, и песни и сам же их исполнял с неповторимой оригинальностью»(Binová 1988, 8).

В последнее время мы наблюдаем повторную волну интереса к творчеству Шукшина с точки зрения литературного возвращения к ценностям, описанными представителями деревенской прозы, которую мы видим не только в многочисленных книжных переизданиях, но и в статьях литературоведов, документальных фильмах, новых вариантах аудиокниг, профессиональных и аматорских постановках его рассказов. О современной популярности произведений Шукшина говорит одноименная песня Павла Ключина «Калина Красная» 2019 года, отражающая тематику тюремного заключения и последующего возвращения к нормальной жизни. С этой композицией исполнитель участвовал в XVI всероссийском конкурсе песни среди осужденных «Калина Красная». Конкурс был назван в честь призведения Шукшина «Калина Красная».

С точки зрения социологии имя Шукшина мы можем рассматривать как определенный бренд, который объединяет потомков автора и имеет позитивное или негативное влияние на реципиентов литературных произведений.

\section{Деревенская проза}

B.М. Шукшин является представителем деревенской прозы, которую многие литературоведы понимают как часть русской литературы, которая выходит за рамки периода 60 - 80(или 50 - 80) годов XX века. И. Н. Иванова пишет: «Советский период XX века «подарил» деревенской теме новые сюжеты - крестьянство в Гражданской войне, коллективизация и раскулачивание, социалистические преобразования на селе, конфликт “городского"с деревенским, гибель “неперспективных" деревень и т.д.»(Ivanova2013, 89).

Н.С. Цветова подчеркивает, что «прошедших десятилетий не хватило, чтобы в полной мереосмыслить неоднородность, глубину и сложность, многосоставность, эволюционность литературного явления, обозначенного многострадальным термином деревенская проза, его укорененность в историко-литературном процессе» (Cvetova 2018, 267 ). Е.А. Андреева наоборот выбирает из критических взглядов: « Резко критикуя почвенничество как идеологически чуждое явление, Д. Быков обличает и подвергает негативной оценке творчество писателейгеревенщиков. На рубеже нового столетия, в переходный период, он осмысляет почвенничество как угрозу» (Andrejeva 2020, 153 ).

Представители деревенской прозы искали ответы на важнейшие вопросы своего времени и одновременно были приверженцами сельского образа жизни. Переезд деревенских жителей в город приносил ссобой автоматический упадок, нехватку рабочей силы и появляющиеся деревни-призраки. Отмеченное нами сокращение жителей уходит корнями в 
новые общественные условия и коллективизацию - процесс объединения крестьянских земель в коллективное хозяйство - так называемые колхозы. Решение о коллективизации было принято на XV съезде КПСС. Самая интенсивная коллективизация проходила в 1930 - 1933 годах и принесла с собой многочисленные жертвы голодомора. Этот процесс повторился после окончания Второй мировой войны в 1945 - 1950 годах в западных областях СССР.

Известным журналом представителей деревенской прозы был ежемесячник «Наш современник».

Русский писатель А. И. Солженицын отмечал: «На рубеже 70-х и в 70-е годы в советской литературе произошел не сразу замеченный, беззвучный переворот без мятежа, без тени диссидентского вызова. Ничего не свергая и не взрывая декларативно, большая группа писателей стала писать так, как если 6 никакого «соцреализма» не было объявлено и диктовано, - нейтрализуя его немо, стала писать в простоте, без какого-либо угождения, каждения советскому режиму, как позабыв о нем. В большой доле материал этих писателей был деревенская жизнь, и сами они выходцы из деревни, от этого (а отчасти и от снисходительного самодовольства культурного круга, и не без зависти к удавшейся вдруг чистоте нового движения) эту группу стали звать деревенщиками. А правильно было бы назвать их нравственниками - ибо суть их литературного переворота была возрождение традиционной нравственности, а сокрушенная вымирающая деревня была лишь естественной, наглядной предметностью» (Solženicyn 2000, 159).

Василий Шукшин обычно воспринимается как сторонник ценностей сельского образа жизни и одновременно как автор своеобразного литературного героя названного Чудиком. Словацкие литературоведы находят, что «персонажи рассказов постоянно оказываются в комическихили трагикомических ситуациях. В.М. Шукшину удалось создать свой собственный тип литературного персонажа - Чудика, для которого окружающий мир иногда очень широк и непонимает его, но который постоянно думает об окружающем мире и стремится найти ответы на актуальные вопросы. В.М. Шукшин смотрит на этих чудаков не только с улыбкой, но и с чувством ностальгии и грусти» (Kusá a kol. 2013, 159).

На наш взгляд, Чудик был одним из многих персонажей, с помощью которых автор стремился показать аутентичную внутреннюю исповедь личности в жизненной ситуации, с которой он сталкивается.

В.М. Шукшин за короткий промежуток времени смог написать несколько рассказов, которые обычно объединяет однословное название мужского героя, характеризующее его: «Чудик» (1967), «Хахаль»(1969), «Хмырь»(1971), «Мастер»(1971), «Дебил»(1971), «Упорный»(1973), «Вечно недовольный Яковлев» (1974). Общим для героев является связь с деревенской средой и попытка внутреннего развития. Каждый из героев стремится к оригинальному решению актуальной жизненной ситуации.

«Для рассказов Шукшина типична следующая композиция: лаконическое авторское введение, монолог героя, в котором он открывается, и заключение. Такая композиция позволяет писателю достичь художественной цели - раскрыть психологию героя, его характер и судьбу. Поэтому автор внимательно следит за речью своего героя, тщательно вводит в свои рассказы их высказывания во всем лексическом, интонационном и стилистическом богатстве. Шукшин опирается на самые жизненные жанры фольклора: устное народное творчество, песни, анекдоты, пословицы. Речь его героя насыщена шутками, колкими словами, кажется, что она впитала все запахи алтайской деревни»(Binová 1988, 136). 
С композиционного угла литературного произведения во всех нами избранных рассказах мы встречаемся с такназываемыми фигуральными парами, «т. е. парами персонажей, которые связаны разными способами: взаимной симпатией, враждой, любовью, завистью и т. п. Это персонажи, которые дополняют друг друга, нуждаются друг в друге. Они не могут существовать друг без друга. Фигуральные пары строятся на принципах параллелей или контрастов»(V̌̌etička 1986, 29).

Литературный тип чудика как прообраз героев Шукшина был введен в литературу самим автором в рассказе под названием «Чудик» (1967), в котором изображен доброжелательный человек. Несмотря на позитивное отношение к жизни, герой вызывает антипатию в своем окружении. Первоначальный юмор постепенно сменяется меланхолией читателя. Интересно, что мы не видим типичную оппозицию счастливая деревня - несчастный город, главный герой Чудик вызывает неодобрение окружающих повсюду. К ключевым рассказам чудиковского типа относят также рассказы «Микроскоп» (1969) и «Срезал» (1970).

Представитель чудиковского типа верен своей сельской среде, он счастлив там. Короткие периоды изменений окружающей среды герой воспринимает как возможность получить доказательства личного счастья в жизни. Конфликта между доброжелательной деревенской и неприветливой городской жизнью не происходит, он предстает как своего рода внутренний магнит невезения:

Жена называла его - «Чудик». Иногда ласково. Чудик обладал одной особенностью: с ним постоянно что-нибудь случалось. Он не хотел этого, страдал, но то и дело влипал в какие-нибудь истории - мелкие, впрочем, но досадные.

Главного героя зовут Василий Егорыч Князев, но почти всегдав данном рассказе он предстает как Чудик. Герой создает композиционную фигуральную параллельную пару со своим братом Дмитрием. Его путешествие из села на Урал - это скопление небольших перипетий, которые частично несут печать судьбы и умножаются непониманием окружающих.

-В письмах можете писать что угодно, а телеграмма - это вид связи. Это открытый текст.

Чудик переписал: Приземлились. Все в порядке. Васятка».

Телеграфистка сама исправила два слова: «Приземлились» и "Васятка». Стало: "Долетели. Василий».

Жизнь деревенского жителя в городе воспринимается совместным взглядом обоих братьев. Город изображается как место различных возможностей, за которые, однако, нужно платить отрицанием своего происхождения, потерей оригинальности, частной жизни и спокойствия. В этом случае авторские чаши весов счастливого существования несклоняются ни в одну из изображенных сторон. Жизнь одного брата продолжается в городе, а другой возвращается в родную деревню после короткого отпуска. Писатель подчеркивает важность короткого юмористического рассказа для проницательного читателя, ссылаясь на культовую статью Виктора Шкловского «Искусство как прием» (1917), рассматривающую метафору и метонимию шляпы.

Зашел в продовольственный магазин, пристроился вочередь. Впереди него стоял мужчина в шляпе, а впереди шляпы- полная женщина с крашеными губами. Женщина негромко, быстро, горячо говорила шляпе:

-Представляете, насколько надо быть грубым, бестактным человеком!

Конфронтация деревни и города продолжается в рассказе "Хахаль», в котором, однако, не отмечается параллельная конфигурация персонажей, а лишь их сопротивление. Гость из 
деревни - Костя Жигунов наблюдает за городской жизнью своего друга детства - зашел $\boldsymbol{k}$ земляку своему Сашке Ковалеву. Город со всеми своими бонусами вольнолюбивых отношений без обязательств, проживания в общежитии и определенной формой сексуальной революции, поначалу кажется очень привлекательным. Позже на такие отношения Костя смотрит как на легкомысленные и испорченные:

Костя слушал девушку... И так бы и слушал, и слушал ее -не надоело бы. Какое тут к черту хахальство! - подумал. - Тут впору - жениться на такой.

Костя покидает друга не прощаясь. Городскую жизнь, казавшуюся ему притягательной, герой постепенно переоценивает как поверхностную. В этом рассказе фигуральная пара сельских жителей разделена по принципу город - деревня. С чувством счастья Костя возвращается в родную деревню. Жизнь в городе показана как жизнь без корней и будущего.

Похожий мотив, вырисовывающий город как место поверхностных любовных отношений для сдержанного деревенского жителя, Шукшин продолжает в рассказе «Хмырь». История происходит по пути из деревни в город в курортном автобусе. Неприметный мужчина старается познакомиться с девушкой, которая к тому же не против этого. Фигуральную пару составляют двое попутчиков - пожилые мужчины, курортники, которые уже в самом начале прервут возможный любовный роман и раскроют ложь кавалера - Курортный фрайерок уже женат. Завязка проявляется в ощущении упущенного шанса. Чувства Хмыря не выражены в произведении. Раздвоенная полярность - один из стариков в своем интеллектуальном выражении жалеет о потеряном шансе ухажера окунуться в недолгое и поверхностное приключение, второй старик глубоко убежден в правоте своих действий и необходимой защите морали в обществе:

Большой мужчина, не скрывая удивления, смотрел на старичка.

- Tы 4mo?

-Да ну вас! Теперь вот больно. Пусть бы уж... веселились, как умеют.

Большой мужчина ничего не сказал. Посмотрел на курносого Хмыря, потом осторожно - назад... Пожал плечами. Он ничего не понял. И стал опять смотреть в окно - на пейзаж.

Новый мотив намечается в рассказе «Мастер». Композиция обычных фигуральных пар расслаивается и дает возможность поразмышлять над вопросами культуры и религии, которые Шукшин разрабатывал во времена атеистической социалистической литературы очень умело и чутко. Он построил в микропространстве структуру представителей духовенства и государственной власти, которые идентичны по своему поведению. Классически изображенный конфликт между городом и деревней заключается в недостаточном восприятии региональных различий централизованной России. Семка Рысь из Чебровки -непревзойденный столяр, пожелавший починить близлежащую церквушку, которая давно не служила религиозным целям. Его интерес к восстановлению устаревшего наследия вызван пребыванием в городе, где он работал плотником у писателя. У него была возможность увидеть ряд стимулов и набросков, осознать важность культурного памятника, мимо которого ежедневно гуляют люди и не воспринимают его. Его стремление к возрождению храма не имело духовного характера, он воспринимал здание как культурное наследие, прекрасный элемент, творение рук древнего мастера, которое можно было передать будущим поколениям после реконструкции. Здесь видим, что с ростом власти и богатства отдельных представителей интерес к благосостоянию общества исчезает. Следуя рекомендациям духовенства, свой путьк восстановлению храма он начинает с правительственных чиновников. Восстановить храм, даже в недуховных целях в 
форме материального культурного наследия, Семке не позволят ни представители духовенства, ни государства, отказав в финансовой помощи. Опытный мастер потрясен до такой степени, что пожимает руку своему старому коварному другу - алкоголю. Его поездка в город как попытка сохранить деревенскую культуру остается безуспешной. То, к чему Семка пришел как самоучка, он не мог реализовать как рядовой гражданин. Мастер Семка во время своих усилий по восстановлению храма создает параллельную пару с древним мастером, автором храма. Герой думает о его возможностях, талантах и целях, догадывается, что он также был подчиненвысшей власти - власти финансов и должностных лиц. Он с горечью осознает, что живет в тех же оковах, что и человек средневековья - в клетке возможностей.

Семка сел на приступку, стал думать: зачем этот каменный прикладок? И объяснил себе так: мастер убрал прямые углы - разрушил квадрат. Так как церковка маленькая, то надо было создать ощущение свободы внутри, а ничтотак не угнетает, не теснит душу, как клетка-квадрат.

Желание восстановить храм - это внутренняя миссия Семки, никто основательно его не поддерживает в этом. Жители деревни безразличны к разлагающейся красоте, их отношение вызвано невежеством, которое, в случае с мастером, было нарушено поездкой в город и получением информации. Нижестоящие церковные и государственные чиновники разделяют энтузиазм друг друга, каждый со своей собственной точки зрения, но они понимают, что закостенелая власти не признает важность местной красоты. Можно сказать, что в рассказе «Мастер» главный герой ведет неравную борьбу с невежеством, незаинтересованностью и финансами. По словах М. Микулашека герои Шукшина «... стремятся не раскрывать механизм социального бытия, а, прежде всего, воздействовать на логику, общий смысл человеческого существования и скрытую природу происходящих событий, универсальное утверждение о мире, раскрывающее вечные смыслы в жизни и обществе человека» (Mikulášek 1986, 13).

Рассказы «Дебил» (1971) и «Упорный» (1973) показываютновую точку зрения Шукшина на противопоставление города и деревни. Принципиальное изменение заключается в том, что в этих рассказах городской человек попадает в сельскую среду. В обоих произведениях герой изображен образованным, умным и довольным новой жизненной ситуацией. Эскалация конфликта происходит, когда коренное сельское население, видя свои недостатки во взаимной конфронтации, особенно в плане образования и широкого кругозора, начинает ненавидеть приезжих из города. В рассказе «Упорный» автор создает параллельную пару между деревенским юношей Митькой Димитриевичем, которого звали Моня (являющийся как бынеким преемником рассказа «Сельские жители»(1962)) и обосновавшимся в деревне инженером. Умелый и сообразительный двадцатилетний молодой человек живет в деревне со своей проворной бабушкой. Семейная жизнь его родителей не была удачной. Он остался на воспитание бабушки уже с раннего детства. Герой обучался в техникуме, бросив учебу устроился шофером в кооператив. В этой истории мы видим, как автор ведет диалог со своим читателем спустя тринадцати лет после выхода вступительного рассказа. Плюсом является то, что несмотря на некоторые неуспехи и ошибки, сельские жители остаются упорными. Благодаря переезду образованных горожан деревня становится лучшим местом для жизни. Отличительное упрямство Мони проявлялось от личной свободы до нарушения государственных указов. Тема ограничения личной собственности - одна из основных тем деревенской прозы, авторы которой, по мнению Солженицына, занимаются этим естественно и ненасильственно.

Вид у Мони был крайне заносчивый и упрямый. Вот уж что у него было, так это было, если ему влетела в лоб какая-то идея, - то ли научиться играть на аккордеоне, то ли, как в 
прошлом году, отстоять в своем огороде семнадцать соток, не пятнадцать, как положено по закону, а семнадцать, сколько у них с бабкой, почему им и было предложено перенести плетень ближе к дому.

Моня хочет доказать, что сможет то, что не смогли сделать до него. Герой решается построить вечный двигатель. В юности он верит в свои безграничные возможности. Его упорству постепенно противопостоят все образованные люди села - все они из приезжих: молодой инженер, его жена - учительница математики, учитель физики.

Учитель физики, очень добрый человек, из поволжских немцев, по фрамилии Гекман, с улыбкой слушал возбужденного Моню... Смотрел в чертеж. Выслушал.

О бесконфликтной сельской среде свидетельствует внимание к этнической принадлежности учителя и его положительная характеристика. После логического проигрыша Моня вышел из конфузной ситуациишутя - он смог вызвать у инженера иллюзию, что случилось чудо и поэтому параллельные персонажи разойдутся друзьями. Короткий рассказ "Дебил» показывает читателю вариации деревенской среды - учителя литературы и обладателя прозвища Дебил, который завидует знаниям и кругозору учителя. «Герой Шукшина находится на распутье. Он уже знает, как он не хочет жить, но он не знает, как нужно жить»(Lejderman 2010, 196).

Об абсурдности ситуации, в которой тюрьма является одним из немногих возможных способов обрести новое мировоззрение и может привести к определенной перспективе и росту общественного признания, говорит следующая сцена:

Засмеют деревенские: они нигде не бывали, шляпа им в диковинку. Анатолий же отработал на Севере по вербовке пять лет и два года отсидел за нарушение паспортного режима - он жизнь видел; знал, что шляпа украшает умного человека.

Купив шляпу, Анатолий стремился обрести социальный статус интеллектуала, при этом побаиваясь реакции окружающих. Понимание того, что его новая шляпа не вызвала волну восторга среди сельских жителей и что с учителем завязались дружеские отношения, привело Анатолия к всплеску гнева и ненависти.

Помолчал и сказал негромко, себе:

- В гробу я вас всех видел. В белых тапочках.

Ситуация между соотношением деревни и городской средой меняется в рассказе «Вечно недовольный Яковлев». Яковлев, приехавший из города в отпуск на родину, вступает в фигуральную пару со своим другом детства - Сергеем. Они визуально и по характеру разделены на мир деревни и добра, города и зла. Яковлев провоцирует противоречия и ссоры, его гнев вытекает из подавленного чувства личной несостоятельности. Сергей - самый уравновешенный, бесконфликтный персонаж Шукшина. Он служит проекцией недостатков Яковлева. Пессимизм героя не порожден городом. Уже из названия читатель узнает, что Яковлев вечно недовольный.

В.М. Шукшин - это не только автор Чудиков, но и Хахалей, Хмырей, Мастеров, Дебилов, Упорных, Вечно недовольных Яковлевых. Автор создал целую сеть персонажей, которые проходят между деревней и городской средой и ищут свое место в жизни.

«В произведении Шукшина концепция истины, которую автор отождествляет с моралью, имеет ключевое значение. Если художник честен, то и его работы - по утверждению Шукшина самые нравственные. Сознательное намерение солгать, сфальшивить, Шукшин считает худшим преступлением писателя, потому что таким образом тот обманывает душу читателя» (Binová $1988,132)$. Тезис Г.П. Биновой о моральном кодексе писателя связывает писателя как личность с группой авторов, которых мы называем представителями деревенской прозы. Все избранные 
рассказы объединенытем, что в их заглавиях вынесен характерный признак главного героя, становящийся темой произведения.

\section{Теория и практика деревенской прозы}

Шукшин задумывается над всеми острыми вопросами деревенской прозы. Его подход ненасильственный и мягкий. В отдельных работах он также затрагивает сложные социальнобытовые проблемы коллективизации, периода голодомора, утери веры, изменения образа жизни и внезапного перемещения населения из сельской местности в неподготовленные города с социальной, общественной, экономической, интеллектуальной точки зрения. Писатель избегает поверхностного разделения на хорошее деревенское и плохое городское. Герой Шукшина способен жить там, где его душа чувствует себя спокойно. Автор отчасти затрагивает гендерные проблемы, еще не называя их так, изображает насилие в семье, вызванное разочарованием мужских персонажей:

Анатолий психовал, один раз «приварил» супруге, сам испугался и долго ласково объяснял ей, что Дебил - так можно называть только дурака-переростка, который учиться не хочет, с которым учителя мучаются. «Какой же я Дебил, мне уж сорок лет скоро! Ну?.. Лапочка ты моя, синеокая ты моя... Свинцовой примочкой надо-глаз-то. Купить?

\section{Выводы}

Отраженные автором темы деревенской прозы, противоречие между городом и деревней, указывают на разрыв между старыми моделями существования и частичной неполной заменой новой системы: вопросы коллективизации и изменения духовных ценностей человека, вымирание функционирующей семьи и села, вызванное внешними факторами. Городская жизнь не является альтернативой деревенской жизни в творчестве Шукшина, это обычно способ временного проживания, приносящий лишь поверхностные выгоды. Композиционные фигуральные пары являются важнейшим элементом для изображения главного героя и его отношения к жизни. Полноценные фигуральные композиционные пары создают только мужские персонажи. Мир женщин второстепенен для автора - он представлен в произведениях незначительно. Сильные женские персонажи принадлежат к представителям сельской среды. Оппозиция города несет в себе элементы упадка.

Василий Шукшин является не только автором чудика, но и многих других изображенных персонажей, для которых местом выживания является деревенская среда, а дальнейшее развитие зависит от возможности реализации в домашней обстановке.

\section{Использованная литература/ References}

\section{Печатные источники:}

ANDREJEVA, Е. А. (2020): Критика Д. Быкова: опыт прочтения современной традиционалистской прозы. In Филология и человек. № 3. Барнаул: Алтайский государственный университет: 2020. 152 - 159 с. ISSN 19927940.

BINOVÁ, G. P. (1988):Творческая эволюция Василия Шукшина: [нравственно-философские искания и жанрово-стилевые особенности художественной системы].Brno: UniverzitaJ.E. Purkyně, 1988. 137 с. Без ISBN. 
CVETOVA, N. S. (2018): Русская традиционная проза второй половины XX века какисторико-литературный феномен. InВестник ВГУ. Серия Филология. Журналистика. № 2. Воронеж: ВГУ, 2018. 66 - 71 c.ISSN 18142958.

IVANOVA, I. N.(2013): Деревенская проза в современной отечественной литературе: конецмифа или перезагрузка? In Филологические науки. Вопросы теории и практики. Тамбов: Грамота, 2013. № 6 (24): в 2-х ч. Ч. І. С. 88-94. ISSN 1997-2911.

KUSÁ, M. (2013):Ruská literatúra 18. - 21. storočia. Bratislava: Veda, 2013. 581 c. ISBN 978-80-224-0967-4.

LEJDERMAN, N. L. (2010). Teorija žanra. Jekaterinburg: Slovesnik, 2010. 904 c. ISBN 978-5-904205-04-1.

MIKULÁŠEK, M. (1986): Литература жизненной правды: идейно-эстетическая концепция и принципы литературы социалистического реализма. In Sborník prací Filozofické fakulty brněnské univerzity. D, Řada literárněvědná. 1986, roč. 35, č. D33, s. 13. Без ISBN.

VŠETIČKA, F. (1986): Kompoziciána. O kompozičnej výstavbe prozaického diela. Bratislava: Slovenský spisovatel', Studia Litteraria, 1986. 272 c. Без ISBN.

\section{Онлайн-источники:}

ВАРЛАМОВ, А. (онлайн): Шукшин: 2019 [онлайн]. Режим доступа: https://akniga.org/varlamov-aleksey [дата обращения: 25.05.2020].

ВАРЛАМОВ, А. (онлайн): Взрыв, пазлом и либель, Василий Шукшин заколдовал, обворожил Россию: 2014 [онлайн]. Режим доступа: https://rg.ru/2014/06/04/shukshin.html [дата обращения: 28.05.2020].

ключин, П. (онлайн): Калина Красная: 2019 [онлайн]. Режим доступа: https://www.youtube.com/watch?v=JYlklu44xWY [дата обращения: 10.05.2020].

СОЛЖЕНИЦЫН, А. И. (онлайн): Слово при вручении премии Солженицына Валентину Распутину:2000, [онлайн]. Режим доступа: https://magazines.gorky.media/novyi_mi/2000/5/slovo-pri-vruchenii-premiisolzheniczyna-valentinu-rasputinu-4-maya-2000.html [дата обращения: 20.05.2020].

шклОВский, В. Б. (онлайн): Искусство как прием: 1917, [онлайн]. Режим доступа: https://philolog.petrsu.ru/filolog/artpass.htm [дата обращения: 10.05.2020].

шУкшИН, В. М. (онлайн): Чудик: 1967 [онлайн]. Режим доступа: http://lib.ru/SHUKSHIN/shukshin_chudik.txt [дата обращения: 10.05.2020].

ШУКшИН, В. М. (онлайн): Хахаль: 1969 [онлайн]. Режим доступа: http://www.weblit.net/writer/2394/book/17387/shukshin_vasiliy_makarovich/hahal [дата обращения: 10.05.2020].

шУкшИН, В. М. (онлайн): Хмырь: 1971 [онлайн]. Режим доступа:

https://www.rulit.me/books/hmyr-read-2224-1.html [дата обращения: 10.05.2020].

шУкшИН, В. М. (онлайн): Мастер: 1971 [онлайн]. Режим доступа: http://lib.ru/SHUKSHIN/master.txt [дата обращения: 10.05.2020].

ШУКшИН, В. М. (онлайн): Дебил: 1971 [онлайн]. Режим доступа: http://rushist.com/index.php/rusliterature/3056-shukshin-debil-polnyj-tekst

[дата обращения: 10.05.2020].

ШУКШИН, В. М. (онлайн): Упорный: 1973 [онлайн]. Режим доступа: http://lib.ru/SHUKSHIN/upornyj.txt [дата обращения: 10.05.2020].

ШУКШИН, В. М. (онлайн): Вечно недовольный Яковлев: 1974 [онлайн]. Режим доступа: https://www.litres.ru/vasiliy-shukshin/vechno-nedovolnyy-yakovlev/ [дата обращения: 10.05.2020].

ДАННАЯ СТАТЬЯ ПОДГОТОВЛЕНА В РАMКАХ ПРОЕКTA KEGA С̌. 021UCM-4/2020 S NÁZVOM TVORBA UČEBNíC PRE RUSKOSLOVENSKÉ SEKCIE BILINGVÁLNYCH A SLOVANSKÝCH GYMNÁZIÍ.

\section{Профиль автора:}

Марианна Фигедыюва, старший преподаватель, к.ф.н. Научные интересы: литературоведение, культурология e-mail: marianna.figedyova@ucm.sk 
Место работы: Университет Св. Кирилла и Мефодия в Трнаве, Трнава, пл. Й. Герду 2, 917 01, Словакия

\section{Author's profile:}

PaedDr. Marianna Figedyová, PhD.

Research interests: literary studies, culturology

e-mail: marianna.figedyova@ucm.sk

Place of work: University of Ss. Cyril and Methodius in Trnava, J. Herdu 2, 917 01, Trnava, Slovakia 